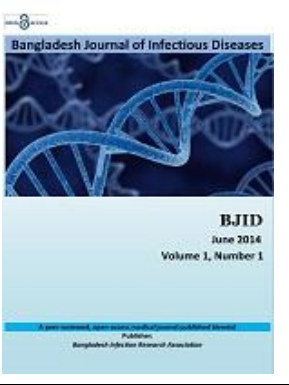

\title{
Clinical and Microbiological Aspect of Wound Infection: A Review Update
}

\author{
Sharmina Aftab ${ }^{1}$, Md. Monowar Tarik ${ }^{2}$, Md. Abdullah Siddique ${ }^{3}$, Md. Abdullah Yusuf ${ }^{4}$
}

${ }^{1}$ Lecturer, Department of Microbiology, Rajshahi Medical College, Rajshahi, Bangladesh; ${ }^{2}$ Junior Consultant (Orthopaedic Surgery) Upazila Health Complex, Tanore, Rajshahi, Bangladesh; ${ }^{3}$ Professor \& Head, Department of Microbiology, Rajshahi Medical College, Rajshahi, Bangladesh; ${ }^{4}$ Assistant Professor, Department of Microbiology, National Institute of Neurosciences \& Hospital, Dhaka, Bangladesh

[Received: 2 January 2014; Reviewed: 23 March 2014; Accepted: 30 April 2014; Published on: 1 December 2014]

\begin{abstract}
Wound infection is frequently found. Infection of the wound happened due to entry of the bacteria through breached skin. These bacteria stop healing and produce sign and symptoms. From the beginning of the civilization scientist are fighting against infection. It is evident that wound infection is a challenging situation for the physicians. Multiple organisms can cause wound infection. For the treatment of infection a large number of antibiotics are used. Both broad spectrum and narrow spectrum antibiotics are available nowadays. It is ideal to give proper antibiotic after culture and sensitivity of the wound swab, pus or infected tissue. Improper and irrational use of antibiotics and genetic and non-genetic drug resistant mechanisms of bacteria lead to drug resistance. Wound infection can be recognized by various sign symptoms. The inflammatory response is a protective mechanism that aims to neutralize and destroy any toxic agents at the site of an injury and restore tissue homeostasis. The classic signs of infection include: localized erythema, pain, heat, cellulitis and oedema. Other criteria include: Abscess, discharge, delayed healing, discolouration of tissues within and at the wound margins, friable \& bleeding granulation tissue. Unexpected pain or tenderness, abnormal smell, wound breakdown wound pocketing are also seen in wound infection. [Bangladesh J Infect Dis 2014;1(2):32-37]
\end{abstract}

Keywords: Clinical impact, wound infection, microorganism

Corresponding author: Dr. Sharmina Aftab, Lecturer, Department of Microbiology, Rajshahi Medical College, Rajshahi, Bangladesh; Email: sharmina.arlin@gmail.com; Cell No.: +8801712016218

[How to Cite this article: Aftab S, Tarik MM, Siddique MA, Yusuf MA. Clinical and Microbiological Aspect of Wound Infection: A Review Update. Bangladesh J Infect Dis 2014;1(2):32-37]

Conflict of Interest: Authors have declared no conflict of interest.

Contributions to authors: SA \& MMT have prepared the manuscript. MAS \& MAY have revised the manuscript. 


\section{Introduction}

Wound infection is a common problem ${ }^{1}$. Infection of the wound happened due to entry of the bacteria through breached skin. These bacteria stop healing and produce sign and symptoms. From the beginning of the civilization scientist are fighting against infection. It is evident that wound infection is a challenging situation for the physicians ${ }^{2}$.

Multiple organisms can cause wound infection ${ }^{3}$. For the treatment of infection a large number of antibiotics are used. Both broad spectrum and narrow spectrum antibiotics are available nowadays. It is ideal to give proper antibiotic after culture and sensitivity of the wound swab, pus or infected tissue. Unfortunately this practice is uncommon among the physicians especially of the developing countries. Improper and irrational use of antibiotics and genetic and non-genetic drug resistant mechanisms of bacteria lead to drug resistance ${ }^{4}$. Drug resistant bacteria are the most important therapeutic challenge in the field of infectious diseases. Many of them are multi drug resistant. Among them MRSA and ESBL producing gram negative bacteria are of major concern. Most wound infections can be classified into two major categories: skin and soft tissue infections, although they often overlap as a consequence of disease progression $^{5}$. Infections of hospital-acquired wounds are among the leading nosocomial causes of morbidity and increasing medical expense.

\section{Definition}

A wound is a break in the integrity of the skin or tissues, which may be associated with disruption of the structure and function ${ }^{6}$. Another way, a wound may be defined as disruption of the normal continuity of bodily structures due to trauma, which may be penetrating or non-penetrating ${ }^{7}$.

\section{History}

Hippocrates (Greek physician and surgeon, 460-377 $\mathrm{BC})$, known as the father of medicine, used vinegar to irrigate open wounds and wrapped dressings around wounds to prevent further injury. His teachings remained unchallenged for centuries. Galen (Roman gladiatorial surgeon, 130-200 AD) was first to recognize that pus from wounds inflicted by the gladiators heralded healing (pus bonum et laudabile ["good and commendable pus"]. Unfortunately, this observation was misinterpreted, and the concept of pus preempting wound healing persevered well into the eighteenth century ${ }^{7}$. The link between pus formation and healing was emphasized so strongly that foreign material was introduced into wounds to promote pus formation and suppuration ${ }^{8}$. The concept of wound healing remained a mystery, as highlighted by the famous saying by Ambroise Pare (French military surgeon, 1510-1590), "I dressed the wound. God healed it". Koch, Professor of Hygiene and Microbiology, Berlin, 1843-1910, first recognized the cause of infective foci as secondary to microbial growth in his nineteenth century postulates. Semmelweish Austrian obstetrician, (1818-1865) demonstrated a 5 fold reduction in puerperal sepsis by hand washing between performing postmortem examinations and entering the delivery room. Joseph Lister (Professor of Surgery, London, 1827-1912) and Louis Pasteur (French bacteriologist, 1822-1895) revolutionized the entire concept of wound infection ${ }^{10}$. Lister recognized that antisepsis could prevent infection. In 1867, he placed carbolic acid into open fractures to sterilize the wound and prevent sepsis. In 1871, Lister began to use carbolic spray in the operating room to reduce contamination ${ }^{11}$. As late as the nineteenth century, aseptic surgery was not routine practice. Sterilization of instruments began in the 1880 s as did the wearing of gowns, masks, and gloves. Penicillin was first used clinically in 1940 by Howard Florey and with the use of antibiotics, a new era in the management of wound infections commenced $^{12}$.

\section{Epidemiology}

In Dhaka, Bangladesh in a study on wound infection four different types of organisms were identified. Highest percentage was Escherichia coli (55.9\%), followed by Pseudomonas spp. (52.9\%), Proteus spp. (38.2\%) and S. aureus (17.6\%). Of the 6 isolates of $S$. aureus $83.3 \%$ were MRSA ${ }^{13}$. A study on "Pattern of aerobic bacteria with their drug susceptibility of surgical inpatients" was carried out in Mymensingh showed rate of wound infection $61.5 \%$. The commonly isolated organisms were Pseudomonas spp., Escherichia coli, Staphylococcus aureus, Klebsiella spp. and others ${ }^{14}$. A study reported that 129 swabs \& pus specimens from various types of surgical sites suspected to be infected on clinical ground were processed and the most common organisms were Staphylococcus aureus $(50.32 \%)$ followed by Pseudomonas aeruginosa (16.3\%), Escherichia coli (14.37\%), Klebsiella pneumoniae (11.76\%), miscellaneous gram negative rods (5.88\%), and Streptococcus pyogenes $(1.30 \%)^{14}$. In another study out of 171 cases of wounds of various etiologies examined and screened bacteriologically $S$. aureus was the most 
frequently isolated (39.9\%) single organism and other organisms being E. coli (26.1\%), Pseudomonas aeruginosa (15.4\%), Klebsiella species (5.8\%), Streptococcus pyogenes (4.9\%), Proteus species $(4.8 \%)$ and coliform organisms $(3.1 \%)$; however, collectively the gram-negative organisms were the majority among the isolated organisms ${ }^{15}$. A study showed wound infection in the post-operative elective surgeries was $11.3 \%$ and the microorganisms found were Staphylococcus aureus $70.5 \%$ and Escherichia coli $29.5 \%{ }^{16}$. In another study showed wound infection rate $23.0 \%$ and isolated organisms were $P$. aeruginosa $29.4 \%$, S. aureus $23.5 \%$, Acinatobacter baumani $16.2 \%$, Escherichia coli $11.8 \%$ and A colcoaceticus $8.8 \%{ }^{17}$. A study has been reported that the surgical site infection rate was $3.03 \%$ in clean surgeries and $22.4 \%$ in clean-contaminated surgeries Staphylococcus aureus was the commonest isolate followed by $P$. aeruginosa and then Escherichia $\operatorname{coli}^{18}$. A study was done on post-operative wound infection showed infection rate $91 \%$ and the most common isolated organisms from postoperative wounds were $P$. aeruginosa $29.6 \%$, Escherichia coli $20.3 \%$, Klebsiella spp. 16.6\%, Staphylococcus aureus $14.3 \%$, Proteus species $6.3 \%$, Acinetobacter spp. 3\% and Citrobacter spp. $0.6 \%^{18}$. Another study showed the overall infection rate of SSIs was $8.29 \%$; however, the infection rate in the wounds following dirty classes were $24.05 \%$ and following clean surgeries were $3.4 \%$ and common pathogens were Staphylococcus aureus (21.5\%), Escherichia coli (21.5\%), Pseudomonas aeruginosa (17.04\%) and Klebsiella pneumoniae $(14.7 \%)^{19}$.

In a study showed that wound infection was $60 \%$ and the organisms isolated from wound were Staphylococcus aureus 50\%, E. coli $11.7 \%$, Pseudomonas aeruginosa $8.3 \%$, S. pyogenes $8.3 \%$, Kl. pneumoniae 6.7\%, CoNS $6.7 \%$ and Proteus species $5 \%^{20}$. In a study with surgical wound infection a high preponderance of aerobic bacteria was observed. Among them the common pathogens were $28.2 \%$ Staphylococcus aureus, $25.2 \%$ Pseudomonas aeruginosa, $7.8 \%$ E. coli, $7.1 \%$ Staphylococcus epidermidis and $5.6 \%$ E. faecalis ${ }^{21}$. Another study showed surgical site infections were $0.9 \%$ of patients undergoing clean surgery and in $3.6 \%$ of patients undergoing clean-contaminated surgery $^{22}$. In Romania 119 bacterial strains isolated from postoperative infected wounds. Regarding their frequency, the strains were isolated $E$. coli 68(57\%) strains, Staphylococcus aureus 37(31\%) strains, Pseudomonas species $9(8 \%)$ strains and Proteus species $5(4 \%)$ strains $^{24}$. In a study in Nigeria, 670 bacterial isolated from 29 patients were studied and the most common isolates were
Pseudomonas spp. $29.9 \%$ and S. aureus $27.5 \%$; in addition to that others were Klebsiella species $18.5 \%$, Proteus species $15.1 \%$, Escherichia coli 7\%, Streptococci 2\% and Enterococci 0.3\%. In USA the overall incidence of SSI has been estimated to be $2.8 \%$ according to the U.S. Centers for Disease control and prevention ${ }^{18}$.

Study on burn wound infection was done in Jordan showed rate of infection was $61.19 \%$ in thirddegree burns and $38.80 \%$ in second degree burns. Pseudomonas was the commonest bacterial cause of invasive burn wound infection followed by Klebsiella spp., Staphylococcus aureus, Proteus and Escherichia coli ${ }^{10}$. A study in Pakistan showed infection rate $9.3 \%$ and $S$. aureus was $24.4 \%$, Pseudomonas aeruginosa 18.6\%, Klebsiella spp. $13.9 \%$ and $E$. coli was in $11.6 \%$ cases $^{12}$.

\section{Classification of Wound}

Wounds can be classified in various ways.

\section{A. According to Rank and Wake ${ }^{13}$ field classification}

1. Tidy wounds: They are wounds like surgical incisions and wounds caused by sharp objects.

2. Untidy wounds: They are due to: Crushing, tearing, avulsion, devitalized injury, vascular injury, multiple irregular wounds, burns etc.

\section{B. Other classification}

1. Clean incised wound

2. Lacerated wounds

3. Bruising and contusion

4. Haematoma

5. Puncture wounds and bites

6. Abrasion

7. Traction and avulsion injury

8. Crush injury

9. War wound

10. Penetrating wounds

11. Others

On the other hand surgeons and doctors have to face various surgical wounds daily. These wounds can be classified as below ${ }^{19}$

- Clean (Class I): Uninfected operative wound; No acute inflammation; Closed primarily; Respiratory, gastrointestinal, biliary, and urinary tracts not entered; No break in aseptic technique Closed drainage used if necessary; Infective risk is $<2 \%$.

- Clean-contaminated (Class II): Elective entry into respiratory, biliary, gastrointestinal, urinary tracts and with minimal spillage; No evidence of infection or major break in aseptic technique; Example: appendicectomy; Infective risk is $<10 \%$.

- Contaminated (Class III): Non-purulent inflammation present; Gross spillage from 
gastrointestinal tract; Penetrating traumatic wounds $<4$ hours; Major break in aseptic technique; Infective risk is about $20 \%$.

- Dirty-infected (Class IV): Purulent inflammation present; Preoperative perforation of viscera; Penetrating traumatic wounds $>4$ hours; Infective risk is about $40 \%$.

\section{Microbiological Impact}

Methicillin resistant Staphylococcus aureus (MRSA), popularly known as super bug, was first recognized at almost the same time that methicillin was marketed for clinical use in 1960. Subsequently large outbreak of MRSA occurred in Britain and Europe in the 1960s. In London in 1961, Jevons reported one resistant strain in 5000 isolates. In the United Kingdom, isolates sent to the Central Public Health Laboratory increased from 3/5440 (0.06\%) in 1960 to $293 / 7153(4.1 \%)$ in 1969 . Screening in eight London teaching hospitals showed that $8.0 \%$ of isolates were methicillin-resistant. Reports of other isolates followed, including reports from Turkey and Poland even though methicillin or any other penicillinase-resistant penicillin was not yet used in these countries. The United States was largely spared of the problem until the mid-1970s, when a number of large hospital wide outbreaks of MRSA infection occurred. The outbreaks reported in the United States in 1970s were confined primarily to large, tertiary-care teaching hospitals. However in 1980s some community hospitals and rehabilitation or extended care facilities experienced an increasing prevalence of MRSA colonization or infections (Jorgensen et al., 1971). In Zurich, the percentage of MRSA isolates increased from $9.7 \%$ in 1965 to $16.1 \%$ in 1967. Resistant strains were common in Denmark (46\% of hospital strains in 1971). In a Sydney hospital, isolates increased from $0.7 \%$ in 1965 , to $5.7 \%$ in 1969 and to $18.5 \%$ by 1970 . An increase in resistant strains was also reported from France and from India. Although resistant strains had been isolated in the USA between 1960 and 1975, reports of outbreaks were rare. At the same time, other workers were reporting a decrease in the number of multiple-resistant methicillin-sensitive strains in the USA and in England. This reduction was thought to be due to the more rational use of antibiotics and improved infection control. However, the issue was complicated in the mid-1970s by the emergence of new strains of MRSA, often resistant to gentamicin, in the U.K., France, and some other countries; in the late 1970s, epidemics were reported in Ireland, Australia and the USA. As in Australia, Ireland and the U.K., control of spread in the USA has been difficult, even with good control facilities. MRSA now represent a global problem (WHO/EMC/LTS/96.1).

\section{Table: List of Wound pathogens Causing Wound Infection ${ }^{16}$}

\begin{tabular}{|c|c|}
\hline $\begin{array}{l}\text { Gram-positive } \\
\text { cocci }\end{array}$ & $\begin{array}{l}\text { Staphylococcus aureus; } \\
\text { Enteroococcus faecalis; } \\
\text { Beta Haemolytic Streptococci } \\
\text { (Streptococcus pyogenes) }\end{array}$ \\
\hline $\begin{array}{l}\text { Gram-negative } \\
\text { aerobic rods }\end{array}$ & Pseudomonas aeruginosa \\
\hline Gram-negative & Escherichia coli \\
\hline facultative rods & $\begin{array}{l}\text { Enterobacter species } \\
\text { Klebsiella species } \\
\text { Proteus species }\end{array}$ \\
\hline Anaerobes & Bacteroides \\
\hline Fungi & $\begin{array}{l}\text { Clostridium } \\
\text { Yeasts (Candida) } \\
\text { Aspergillus }\end{array}$ \\
\hline
\end{tabular}

\section{Clinical Impact}

Different terms are used for description of wound infection. Since 1985 the most commonly used terms have included wound contamination, wound colonization, wound infection and, more recently, critical colonization. These terms can be defined as:

- Wound contamination-the presence of bacteria within a wound without any host reaction ${ }^{10}$

- Wound colonization-the presence of bacteria within the wound which do multiply or initiate a host reaction $^{11}$

- Critical colonization-multiplication of bacteria causing a delay in wound healing usually associated with an exacerbation of pain not previously reported but still with no overt host reaction ${ }^{12}$.

- Wound infection-the deposition and multiplication of bacteria in tissue with an associated host reaction ${ }^{11}$

Wound infection can be recognized by various sign symptoms. The inflammatory response is a protective mechanism that aims to neutralize and destroy any toxic agents at the site of an injury and restore tissue homeostasis. The classic signs of infection include localized erythema, pain, heat, cellulitis and oedema and other criteria include abscess, discharge, delayed healing, discolouration of tissues within and at the wound margins, friable $\&$ bleeding granulation tissue ${ }^{21}$. Unexpected pain or tenderness, abnormal smell, wound breakdown wound pocketing are also seen in wound infection. 
The above criteria should be used as discriminating factors when the 'classic' signs of wound infection are absent but the presence of a wound infection is suspected $^{24}$.

Burn injury is a major problem in many areas of the world. Thermal injury destroys the physical skin barrier that normally prevents the invasion of micro-organisms. However, gram-positive in the depths of sweat glands and hair follicles may survive the heat of initial injury and unless topical antimicrobial agents are applied, these bacteria heavily colonize the wounds within the first $48 \mathrm{~h}$ post-injury ${ }^{20}$. The organisms that predominate as causative agents of burn wound infection in any burn wound treatment facility change over time. Gram positive bacteria are initially prevalent and are then gradually superseded by gram negatives ${ }^{22}$.

\section{Conclusion}

In the conclusion it can be said that the clinical and microbiological aspect of wound infection are very wide range. Multiple bacteria as well as other organism cause different wound infection. Proper wound management should be implemented to combat this problem.

\section{References}

1. Giacometti A, Cirioni O, Schimizzi A, Del Prete M, Barchiesi F, D'errico $M$, et al. Epidemiology and microbiology of surgical wound infections. Journal of clinical microbiology. 2000;38(2):918-22

2. Greif R, Akça O, Horn E-P, Kurz A, Sessler DI. Supplemental perioperative oxygen to reduce the incidence of surgical-wound infection. New England Journal of Medicine. 2000;342(3):161-7

3. Melling AC, Ali B, Scott EM, Leaper DJ. Effects of preoperative warming on the incidence of wound infection after clean surgery: a randomised controlled trial. The Lancet. 2001;358(9285):876-80

4. Atiyeh BS, Costagliola M, Hayek SN, Dibo SA. Effect of silver on burn wound infection control and healing: review of the literature. burns. 2007;33(2):139-48

5. Cutting KF, White R. Defined and refined: criteria for identifying wound infection revisited. Br J Community Nurs. 2004;9(3):S6-15

6. Sorensen LT, Karlsmark T, Gottrup F. Abstinence from smoking reduces incisional wound infection: a randomized controlled trial. Annals of surgery. 2003;238(1):1

7. Smith RL, Bohl JK, McElearney ST, Friel CM, Barclay MM, Sawyer RG, et al. Wound infection after elective colorectal resection. Annals of surgery. 2004;239(5):599
8. Weinstein MA, McCabe JP, Cammisa Jr FP. Postoperative spinal wound infection: a review of 2,391 consecutive index procedures. Journal of Spinal Disorders \& Techniques. 2000;13(5):422-6

9. Bowler P, Duerden B, Armstrong D. Wound microbiology and associated approaches to wound management. Clinical microbiology reviews. 2001;14(2):244-69

10. Estahbanati HK, Kashani PP, Ghanaatpisheh F. Frequency of Pseudomonas aeruginosa serotypes in burn wound infections and their resistance to antibiotics. Burns. 2002;28(4):340-8

11. Rojas I-G, Padgett DA, Sheridan JF, Marucha PT. Stressinduced susceptibility to bacterial infection during cutaneous wound healing. Brain, behavior, and immunity. 2002;16(1):74-84.

12. Edwards R, Harding KG. Bacteria and wound healing. Current opinion in infectious diseases. 2004;17(2):91-6

13. Atiyeh BS, Costagliola M, Hayek SN, Dibo SA. Effect of silver on burn wound infection control and healing: review of the literature. burns. 2007;33(2):139-48

14. Hanifah YA. Post-operative surgical wound infection. Med J Malaysia. 1990;45(4):293-7

15. Malone DL, Genuit T, Tracy JK, Gannon C, Napolitano LM. Surgical site infections: reanalysis of risk factors. Journal of Surgical Research. 2002;103(1):89-95

16. Wilson A, Gibbons C, Reeves B, Hodgson B, Liu M, Plummer D, et al. Surgical wound infection as a performance indicator: agreement of common definitions of wound infection in 4773 patients. Bmj. 2004;329(7468):720

17. Polk Jr HC, Christmas AB. Prophylactic antibiotics in surgery and surgical wound infections. The American Surgeon. 2000;66(2):105-11

18. Mendonça G, Nunes L, Komatsuzaki F. SURGICAL WOUND INFECTION. Modelling Efficiency \& Quality in Health Care. 2003:103

19. Smyth E, Emmerson A. Surgical site infection surveillance. Journal of Hospital Infection. 2000;45(3):173-84

20. Feil W, Koller L, Laciny S, Neumark J, Niedermayer F, Rapf $\mathrm{S}$, et al. Supplemental perioperative oxygen to reduce the incidence of surgical-wound infection. $\mathrm{N}$ engl $\mathbf{J}$ med. 2000;342(3):161-7

21. Guo S, DiPietro LA. Factors affecting wound healing. Journal of dental research 2010;89(3):219-229

22. Siddiqui AR, Bernstein JM. Chronic wound infection: facts and controversies. Clinics in dermatology 2010;28(5):519-526

23. ter Gunne AFP, Mohamed AS, Skolasky RL, van Laarhoven CJHM, Cohen DB. The presentation, incidence, etiology, and treatment of surgical site infections after spinal surgery. Spine 2010;35(3):13231328

24. Horseman MA, Surani S. A comprehensive review of Vibrio vulnificus: an important cause of severe sepsis and skin and soft-tissue infection. International Journal of Infectious Diseases 2011;15(3):e157-e166 